\title{
Subjective Perceptions in Wartime Negotiation
}

\author{
Ning Wang \\ Curious Lab LLC
}

\author{
David V. Pynadath \\ Institute for Creative Technologies \\ University of Southern California
}

\author{
Stacy C. Marsella \\ Institute for Creative Technologies \\ University of Southern California
}

\begin{abstract}
The prevalence of negotiation in social interaction has motivated researchers to develop virtual agents that can understand, facilitate, teach and even carry out negotiations. While much of this research has analyzed how to maximize the objective outcome, there is a growing body of work demonstrating that subjective perceptions of the outcome also play a critical role in human negotiation behavior. People derive subjective value from not only the outcome, but also from the process by which they achieve that outcome, from their relationship with their negotiation partner, etc. The affective responses evoked by these subjective valuations can be very different from what would be evoked by the objective outcome alone. We investigate such subjective valuations within human-agent negotiation in four variations of a wartime negotiation game. We observe that the objective outcomes of these negotiations are not strongly correlated with the human negotiators' subjective perceptions, as measured by the Subjective Value Index. We examine the game dynamics and agent behaviors to identify features that induce different subjective values in the participants. We thus are able to identify characteristics of the negotiation process and the agents' behavior that most impact people's subjective valuations in our wartime negotiation games.
\end{abstract}

\section{INTRODUCTION}

Negotiation is ubiquitous in everyday social interaction, whenever people must decide how to allocate resources in contention [1]. As a result, the artificial intelligence community has conducted a great deal of work on using virtual agents to understand, facilitate, teach and even carry out negotiations [2], [3], [4], [5], [6]. Most of this research has naturally used the allocation outcome of a negotiation as an objective measure that an agent can model and optimize.

However, negotiation also generates subjective perceptions of this objective outcome, including social psychological values like perceptions of the bargaining situation, the other party, and oneself [7]. Subjective assessments of these values may evoke affective responses that differ from the responses evoked by the objective outcome in isolation. For example, an objective increase in resources may be outweighed by a negative affective response when it comes at the expense of a family member with whom the subjective value of the interpersonal relationship is more important [8]. Affective features play a role in human-agent negotiation as well, where, for example, a virtual agent's emotional display has been shown to sway people's decision-making [9], [10].

Therefore, an agent must take these subjective perceptions into account when modeling its human counterpart's decision-making. Modeling only the objective outcome is a dangerous approximation, as it has been shown to be poorly correlated with these subjective perceptions [11]. With an incorrect model of its partner's subjective values, an agent can evoke negative affective responses that may, in turn, lead to negotiation failures and diminished objective outcomes.

An agent that cannot model these perceptions will be at a further disadvantage because the subjective outcome, not the objective one, has shown to be a better indicator of future successful negotiations [12]. Future negotiation is more likely to take place if the negotiators establish the foundation for a relationship in the current negotiation [13]. For example, an agent may be able to gain greater returns in the long run by sacrificing immediate gains to evoke positive affective responses in its negotiation partner.

It is thus important for intelligent virtual agents to accurately model a person's subjective perceptions and the affective responses they trigger. In this paper, we investigate potential features of such a model by analyzing humanagent interaction in a wartime negotiation scenario that has been previously subjected to game-theoretic analyses [14], [15] and experimental measurement of objective outcomes [16]. The wartime setting augments the negotiation with an external process that allows non-negotiation moves (e.g., attack) and triggers exogenous events (e.g., military defeat). This process provides a novel dimension of outcomes that will trigger a different class of subjective perceptions, as well as evoke fundamentally different affective responses.

In examining human behavior within wartime negotiation, we first verify previous findings that objective outcomes do not always correlate well with subjective perceptions, which we measure via the Subjective Value Index (SVI) [11]. Next, drawing inspiration from the negotiation literature [17], [18], we hypothesize framings of objective outcomes that might better correlate with measured subjective values. Then by controlling for the objective outcome, we identify characteristics of the negotiation process and agent behavior that lead to differences in subjective value. We thus pinpoint features that influence participants' perceptions of the wartime negotiation process beyond the objective outcomes.

\section{WARTIME NEGOTIATION}

A number of formal models in the literature represent war as a costly process embedded within a negotiation 


\begin{tabular}{|c|c|c|c|c|}
\hline & Powell28 & Powell72 & Slantchev28 & Slantchev72 \\
\hline Start & $28 \%$ & $72 \%$ & $28 \%$ & $72 \%$ \\
\hline War & \multicolumn{2}{|c|}{$\begin{array}{l}\text { Single battle can end the } \\
\text { war in a win/loss for the } \\
\text { player }\end{array}$} & \multicolumn{2}{|c|}{$\begin{array}{l}\text { Single battle changes military } \\
\text { position }(0-10) \text {, with } 10(0) \\
\text { being a win (loss) for player }\end{array}$} \\
\hline Battle & \multicolumn{2}{|c|}{$\begin{array}{l}\text { Battle occurs only if either } \\
\text { side unilaterally initiates }\end{array}$} & \multicolumn{2}{|c|}{$\begin{array}{l}\text { Battle occurs every round, not } \\
\text { initiated by either side }\end{array}$} \\
\hline Offers & \multicolumn{2}{|c|}{ Agent cannot counteroffer } & \multicolumn{2}{|c|}{ Agent must counteroffer } \\
\hline
\end{tabular}

Table I

GAME FEATURES ACROSS THE FOUR CONDITIONS

between two sides over the division of a desirable resource. In this work, this resource is a disputed territory, which is initially split between them in a certain ratio. The wartime negotiation progresses round by round, with each round consisting of one side offering a percentage of territory to the other side, the other side responding to that proposal, and a possible battle between the two. The negotiation process ends with a final split achieved by either the acceptance of an offered amount or a decisive military victory on the battlefield (where the victor receives all of the territory). Furthermore, each round with a battle causes both sides to incur costs, which the negotiation interface presents to the human players in terms of 2,000 troops lost per round (after starting with 40,000). This cost of battle and the possibility of a military settlement to the dispute provide a novel pressure on both sides, who must consider these external factors within their decision-making at the negotiation table.

We implemented two wartime negotiation models, Powell [14] and Slantchev [15], selected due to their impact on the field and their suitability for a human-agent game interaction. These two models provide different game dynamics, diversifying the affective components of the agent-player relationship. We implemented both games within PsychSim, a multiagent framework for social simulation [19]. PsychSim agents have their own goals, beliefs, and a theory of mind that allows them to recursively model other agents (e.g., their goals, beliefs, etc.), form expectations about their behavior, and choose optimal actions as a best response.

In combination with these two models, we also varied the territory owned by the human player at the start of the game, either $28 \%$ or $72 \%$, to vary the potential reference points [18] and anchors [17] that play an important role in the participants' affective responses (detailed explanation hereafter). In addition, we imposed a maximum of 15 rounds per game. If 15 rounds complete without an agreement or a complete military victory, then both sides settle with what they have started. Table I shows the distinguishing battle and offer mechanics of the four possible experimental conditions.

\section{HYPOTHESES}

Based on the features of this negotiation task, we make four a priori hypotheses about affective factors influencing the participants' subjective values. We first examine the relationship between the objective and subjective values:
Hypothesis 1: There is a positive correlation between the territory the human player has at the end of the game and their SVI ratings. However, in line with previous work, we expect these correlations to be relatively weak [11].

This expected weak correlation suggests that there are factors beyond the absolute objective outcomes that are driving the participants' affective outcomes. Reference points constitute one such factor investigated in the literature to model positive perceptions of outcomes above a threshold and negative perceptions of those below [20], [17], [18]. One such reference point is the status quo, the territory the human player starts with. In other words, participants who use their starting territory as a reference point would have positive perceptions of ending up with $50 \%$ of the territory after starting with only $28 \%$, but negative perceptions of that same objective outcome when starting with $72 \%$.

Hypothesis 2: There is a positive correlation between the change in the participants' territory between the start and end of the game and their SVI ratings.

Another reference point investigated in the literature is the initial offer [18]. This reference point will give participants positive perceptions when they give up less territory than they initially offered, and negative perceptions otherwise. ${ }^{1}$

Hypothesis 3: There is a positive correlation between the participants' SVI ratings and the difference between $(100 \%$ - their initial offer) and their ending territory.

One advantage of the wartime aspect of this negotiation setting is that there are two different mechanisms for resolving the dispute, at the negotiation table or on the battlefield, with potentially different affective responses. We would expect participants to have a positive emotional response to reaching an agreement, and we expect them to have negative responses to failing to reach an agreement, whether due to the game ending through war or through running out of time.

Hypothesis 4: When the game ends with both sides reaching an agreement, the participants' SVI ratings will be higher than when the game ends with no agreement.

Testing these four hypotheses will give us initial insight into possible affective components of the participants' subjective values. To dig deeper into these subjective values, we will cluster the games according to their objective outcomes and examine each cluster for distinguishing characteristics. By observing correlations with SVI within such clusters, we can identify features that influence the participants' subjective values independent of the objective outcomes.

\section{METHOD}

We recruited 240 participants, of an average age of 35, via Amazon Mechanical Turk. 51\% of the participants are female and $49 \%$ male. $65 \%$ are from the United States, $29 \%$ from India and $6 \%$ from other countries. $12 \%$ have some

\footnotetext{
${ }^{1}$ The initial offer would also constitute a potential anchor [17] that influences subsequent offers, but we do not investigate that relationship.
} 
high school or high school diploma; $63 \%$ have some college or college degree and $25 \%$ have some graduate school or graduate degree. $13 \%$ use a computer for 1-4 hours a day, $43 \%$ for 5-8 hours a day and $44 \%$ for $>8$ hours a day.

Each participant is assigned an anonymous ID, reads the information sheet about the study, and fills out a Background Survey. Next the participant plays the negotiation game four times, each time with a different condition of Table I (the order is randomized). The game interface presents the participants with the troops and territory they own, as well as the number of rounds left and the history of previous offers and battle outcomes (they do not know, a priori, how many troops they will lose in each battle). There is no implication in the instructions that the participant would be playing against another human player. During the negotiation, the participant fills out an In-Game Survey. Following each negotiation game, the participant fills out an Opinion Survey. The study is designed to be completed within an hour, although the average duration was 32 minutes in our data.

1) Background Survey: asks for the participant's age, gender, nationality, education, computer experience, Attitude Towards War [21], Social Orientation [22] and attitude towards Inappropriate Negotiation (SINS, from [23]).

2) Opinion Survey: contains questions regarding the participant's goals during the game and modified questions from the Subjective Value Index (SVI) survey [11] regarding Outcome, Process, Relationship and Self. SVI-Outcome indicates how participants feel about the game outcome. SVIProcess indicates how participants feel about the negotiation process during the game. SVI-Relationship indicates how participants feel about the relationship with the opponent as a result of the game. And SVI-Self indicates how participants feel about themselves as a result of the game (e.g., "Did this negotiation positively or negatively impact your selfimage or your impression of yourself?"). The self-report on SVI is valued between 1 and 7 . Higher values indicate that participants feel better about the issue.

3) In-Game Survey: asks the participant to estimate the opponent's response after he/she takes an action. For example, after the participant makes an offer, he/she estimates whether the opponent will accept the offer, reject it or attack.

4) Game Logs: capture all actions taken by both sides and world states, e.g. the troops and territory of each side.

\section{Results}

From our study's 240 participants, we have 238 games in the Powell72 condition and 239 games each in Powell28, Slantchev72, and Slantchev28. On average, participants ended with $34.14 \%$ of the territory $(S T D=34.28)$ after losing 5,413 troops $(S T D=5,911)$. Game order did not interact with experiment manipulation on participants' SVI values, except for SVI Relationship, which increased from game 1 to game $4(p=.0113)$. Overall, the SVI values are significantly correlated across the multiple dimensions (Table II) - a result similar to the one found in the original SVI study where the instrument was developed [11]. However, the strengths of these correlations are highly variable, indicating that there is different information content in each dimension.

\begin{tabular}{ll|rc}
\hline Variable & by Variable & Correlation & $p$ \\
\hline SVI Self & SVI Outcome & 0.5799 & $<.0001$ \\
SVI Process & SVI Outcome & 0.7201 & $<.0001$ \\
SVI Process & SVI Self & 0.5468 & $<.0001$ \\
SVI Relationship & SVI Outcome & 0.6672 & $<.0001$ \\
SVI Relationship & SVI Self & 0.5344 & $<.0001$ \\
SVI Relationship & SVI Process & 0.8083 & $<.0001$ \\
\hline \multicolumn{3}{c}{ Table II } \\
\multicolumn{3}{c}{ CORRELATION BETWEEN SVI VARIABLES. }
\end{tabular}

\section{A. Correlation of SVI with Objective Outcomes}

In verifying Hypothesis 1, we see that the participants' objective game-ending territory is positively correlated with their self-reported SVI variables. Thus, as expected, the more territory the participants get, the happier they are with the outcome $(r=0.3528, p<.0001)$, the negotiation process $(r=0.3444, p<.0001)$, the relationship with the opponent $(r=0.2499, p<.0001)$ and themselves $(r=0.1149$, $p=.0004)^{2}$. The correlation strength ranges from weak to medium across these results, as expected and in line with previous work on subjective values in negotiation [11].

\section{B. Correlation of SVI with Reference Points}

For Hypothesis 2, we measure how much territory the participants gained with respect to the status quo reference point. This is calculated by subtracting the territory they started with $(28 \%$ or $72 \%)$ from the territory they ended with. On average, participants lost $15.97 \%$ of the territory $(S T D=34.19)$. The territory gains are weakly correlated with the outcome $(r=.2145, p<.0001)$, the negotiation process $(r=.1678, p<.0001)$, the relationship with the opponent $(r=.0884, p<.0067)$. The correlation with how participants view themselves (SVI-Self) is not statistically significant ( $r=.0576, p=.0757)$. Compared to the correlation with absolute territory owned at the end of the game (see Section $\mathrm{V}-\mathrm{A}$ ), these correlations are significantly weaker according to Steiger's Z-tests ( $p<.01$ for all four).

Hypothesis 3's initial offer reference point compares the territory participants gave up against how much they first offered. We subtract the participants' initial offer from $100 \%$, to compute the territory they would have kept if accepted. There is a significant difference in this "initial kept" territory between games started with $28 \%$ and $72 \%\left(\right.$ Mean $_{28}=65.85$, Mean $\left._{72}=72.05, p<.0001\right)$. When participants started with $72 \%$ of the territory, they initially try to keep the amount of territory they started with. However, when they started with

\footnotetext{
${ }^{2}$ We also analyzed the correlations using troops lost as an objective outcome. The result is similar to that of territory in that the average troop loss is negatively correlated with the SVI Outcome $(r=-0.3596$, $p<.0001)$, Process $(r=-0.4492, p<.0001)$, Relationship $(r=-0.4727$, $p<.0001)$ and themselves $(r=-0.2716, p<.0001)$.
} 
$28 \%$, they seek significant gains, in fact almost as much territory as in the $72 \%$ condition. Overall, the difference between the participants' ending territory and their initial kept territory is positively correlated with SVI outcome $(r=0.4146, p<.0001)$, negotiation process $(r=0.4255$, $p<.0001)$, relationship with the opponent $(r=0.3759$, $p<.0001)$ and themselves $(r=0.2413, p<.0001)$. Steiger's Z-tests show that these correlations are stronger than the correlations with the absolute objective outcomes of Section $\mathrm{V}-\mathrm{A}$ ( $p<.01$ for all four), providing evidence for the participant's initial offer being a reference point.

\section{Comparison of SVI with/without an Agreement}

We examine Hypothesis 4 to determine whether reaching an agreement influenced participants' SVI ratings. First, we categorize the games based on whether they ended with an agreement or not. Out of 955 total games, 520 ended with an agreement $(54.4 \%)$ and 435 (45.6\%) ended without. In the end, when the games ended with an agreement, the participants felt better about the outcome $(p<.0001$, $M e a n_{\text {With }}=4.35, M e a n_{\text {Without }}=3.52$ ), the negotiation process $\left(p<.0001\right.$, Mean $_{\text {With }}=4.82$, Mean $\left._{\text {Without }}=3.01\right)$, their relationship with the opponent $\left(p<.0001\right.$, Mean $_{\text {With }}=4.42$, Mean $\left._{\text {Without }}=2.26\right)$ and even themselves $(p<.0001$, Mean $_{\text {With }}=4.41$, Mean $_{\text {Without }}=3.89$ ). It is thus clear that reaching an agreement improved the participants' subjective perceptions across all the SVI dimensions.

\section{Controlling for Objective Outcome}

The data bore out our hypotheses regarding the correlations between aggregate outcomes and the participants' subjective perceptions, but the relative weakness of these correlations indicates that there are other factors influencing those perceptions. For example, while Section V-C showed that reaching an agreement led to more positive perceptions, it is possible that games ending with an agreement coincidentally resulted in more territory for the participants than games without. To isolate the influence of objective outcomes, we clustered the games into four categories according to how much territory participants ended with:

All: $\quad$ Participant ended with $100 \%$ of the territory and the agent got $0 \%$.

High: Participant ended with higher than average (but $<$ $100 \%$ ) of the territory.

Low: Participant ended with lower than average (but $>$ $0 \%$ ) of the territory.

None: Participant ended with $0 \%$ of the territory and the agent got $100 \%$.

Figure 1 shows the mean SVI ratings across these categories.

1) Agreement and SVI: First, to remove the effect of objective outcomes, we conducted an ANCOVA to study the effect of reaching an agreement in isolation. The result is similar to that of Section V-C, namely that SVI ratings are significantly higher when an agreement is reached
( $p<.0001$ for all four comparisons). However, breaking down the comparison into our four outcome categories, more interesting results emerge. Figure 1 shows that those who ended with All the territory actually reported lower ratings on SVI Outcome, Process, Relationship, and Self ( $p<.0001$ for all four) than those who ended with a High percentage of the territory. In fact, the ratings from those who ended up with All the territory are not significantly different from those who ended up with a Low percentage of the territory on SVI Outcome $(p=.4018)$ and SVI Process $(p=.1382)$, and are even lower on SVI Self $(p=.0087)$ and SVI Relationship $(p<.0001)$. Examining this seemingly counterintuitive result, we first observe that participants end up with $A l l$ of the territory exclusively by a military victory ending the game. When participants end with a High or Low percentage of territory, they do so almost exclusively by reaching an agreement with the agent (see Figure 2). Thus, the lower subjective values for the All case confirm Section V-C's earlier results on the impact of agreement on SVI ratings. In other words, even though the participants "won" the negotiation by getting all of the territory, the failure to reach an agreement caused the participants to take a more negative view of the negotiation than when they achieved a worse objective outcome, but did so through an agreement.

The difficulty in reaching an agreement with the agent could also play a role. People often have a negative affective response to a negotiation partner who refuses to "budge", as modeled in previous PsychSim negotiation agents [24]. Indeed, when the games ended with an agreement, SVI Outcome $(r=-.4257, p<.0001)$, Process $(r=-.5520$, $p<.0001)$, Relationship $(r=-.5352, p<.0001)$ and Self $(r=-.2991, p<.0001)$ are all negatively correlated with how long it took to reach the agreement (represented by the number of rounds required to reach the agreement).

2) Initiation of War and SVI: One factor that can influence SVI ratings is whether participants were attacked by the agent. In particular, if the agent initiated an attack against the participants, the participants may cast blame on the agent. Such blame is unlikely in the Slantchev model, where both sides must engage in battle every round. We therefore focus this analysis on only the Powell Model. Overall, the agent initiated the attack in $35 \%$ of the games and the player initiated the attack in $40 \%$ of the games. In the remaining $25 \%$ of the games, neither side attacked the other. Figure 3 shows the SVI values from Powell games where there was no attack, or where attack was initiated by the player or by the agent. Interestingly, when there are no attacks, the SVI ratings on Outcome, Process, Relationship and Self are all higher than when one side attacked the other, regardless of who initiated the attack $(p<.0001$ for all 8 pairs of comparison). There is no significant difference in SVI ratings between games where the player initiated the attack and the ones where the agent initiated the attack. These similar subjective values are especially surprising 


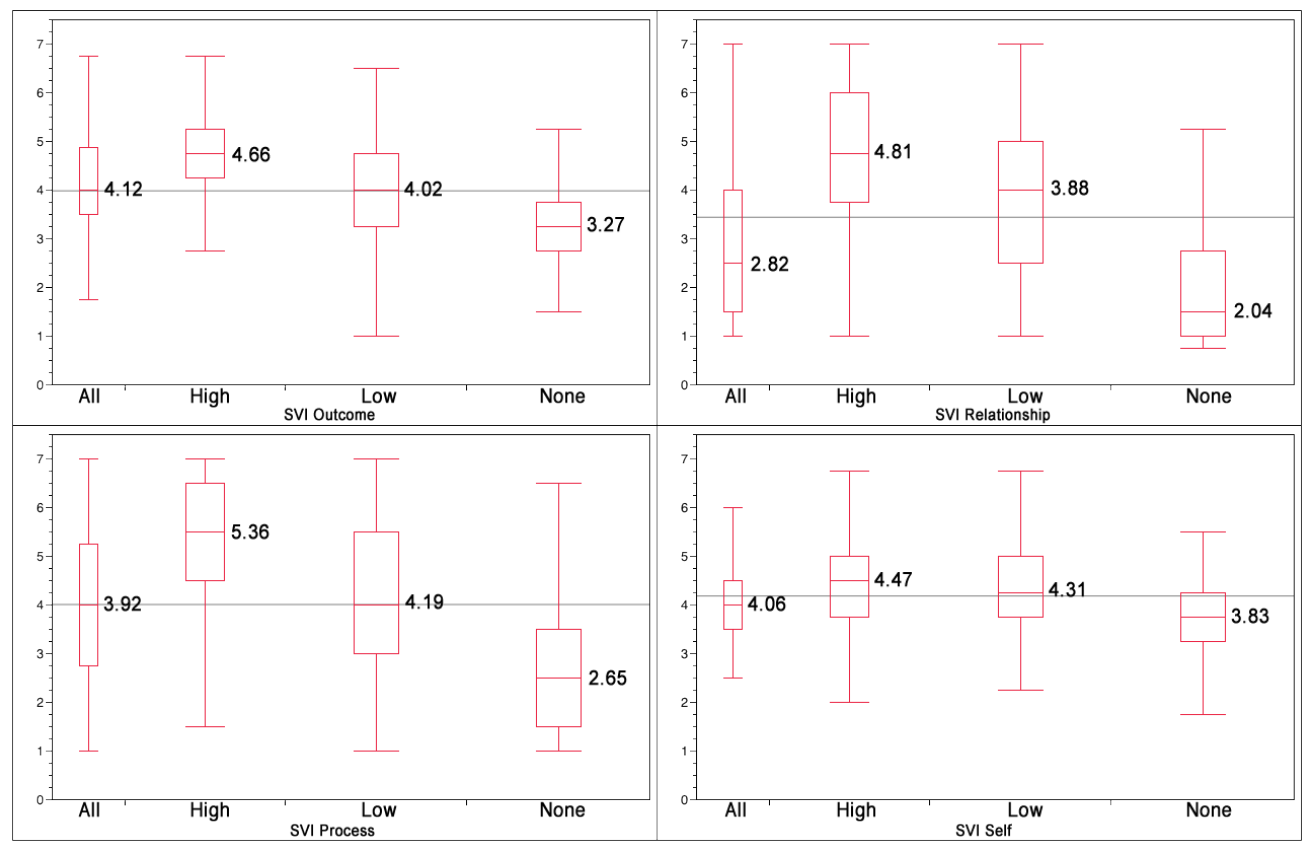

Figure 1. Self-report of SVI variables for games of various endings.

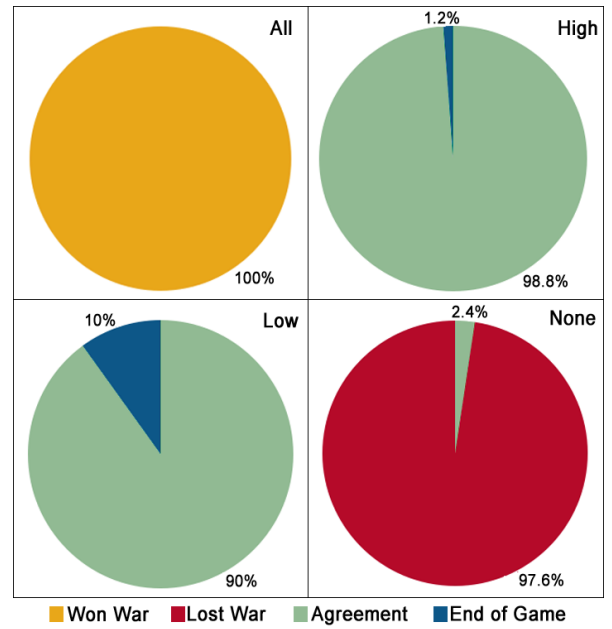

Figure 2. Distribution of how games end categorized by the territory participants have at the end of the game. The "End of Game" category means that the game ended when it reached 15 rounds.

given the uneven distribution of attack initiation across different objective outcomes. In particular, the participants did not initiate attack in games where they ended up with High territory, while the agent did not initiate attacks in the games where the participants ended up with Low territory. Due to the uneven distribution of attack initiation, we did not break down the comparison within groups of different objective outcomes. However, subsequent ANCOVA tests show that, after controlling for the effect of the participants' final territory, the same patterns of differences remain $(p<.0001$ for all 8 pairs of comparison). When there is no attack, participants are significantly more satisfied with the Outcome, Process, Relationship and themselves, compared to when one side attacked the other.

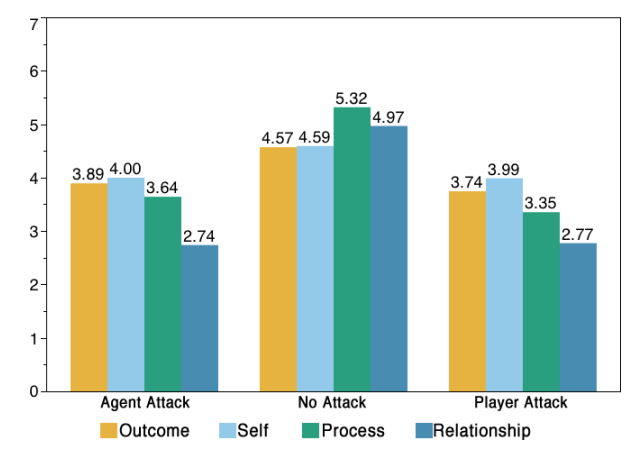

Figure 3. Mean SVI ratings based on who initiated attack.

\section{CONCLUSION}

In this paper, we studied the relationship between the objective and subjective outcomes in a wartime negotiation game. Our data replicated the findings in the negotiation literature that the correlation between the two are positive but weak. We then analyzed additional features of the negotiation dynamics that might influence the participants' subjective values. For example, we examined possible reference points that might bias the participants' perceptions of the outcome, and observed that the human player's initial offer showed the most influence on those perceptions. We also observed that reaching an agreement (as opposed to achieving a military resolution) played a critical role in the participants' subjective values, to the point of often outweighing the objective outcome. While the participants derived the expected negative values when attacked by the agent, they derived similar negative values when they themselves were the attackers. Thus, we have evidence that the participants placed a value on "peace", rather than just resenting being attacked by the other side. 
These conclusions give us insight into the design of intelligent negotiation agents that can take subjective values into account. One obvious follow-on study is to explicitly model these subjective values within the PsychSim agent, so that it can choose its actions to achieve not only objective gains, but to also positively influence the human player's perceptions. Repeating the current experimental setup with this modified agent would allow us to measure the ability of this new agent to evoke positive affective responses.

One distinguishing characteristic of our investigation is the use of a wartime negotiation scenario for our empirical study. Many prior studies of human behavior have sought to reduce the human-agent interaction to a minimal number of dimensions, as in games like the Prisoner's Dilemma, with only two moves and four outcomes. In this work, we instead expand the space of interaction by embedding the negotiation process within an external war setting that enrich the space of moves and outcomes. While this expansion also introduces new confounding interdependencies, we have shown that it is still possible to isolate the dimensions of interest and identify conclusive effects. As a result, the additional richness of the wartime setting was able to provide us with unique insights into how people form their subjective perceptions of the process and outcomes of negotiation.

\section{ACKNOWLEDGMENTS}

This work was sponsored by the U.S. Army Research, Development, and Engineering Command (RDECOM). The content does not necessarily reflect the position or policy of the Government. No official endorsement should be inferred.

\section{REFERENCES}

[1] D. G. Pruitt, "Achieving integrative agreements," in Negotiating in organizations. Sage, 1983, pp. 35-49.

[2] T. Bickmore, D. Mauer, F. Crespo, and T. Brown, "Negotiating task interruptions with virtual agents for health behavior change," in AAMAS, 2008, pp. 1241-1244.

[3] M. Core, D. Traum, H. C. Lane, W. Swartout, J. Gratch, M. Van Lent, and S. Marsella, "Teaching negotiation skills through practice and reflection with virtual humans," Simulation, vol. 82, no. 11, pp. 685-701, 2006.

[4] C. M. Jonker, K. V. Hindriks, P. Wiggers, and J. Broekens, "Negotiating agents," AI Mag, vol. 33, no. 3, pp. 79-91, 2012.

[5] L. Miller, S. Marsella, T. Dey, P. Appleby, J. Christensen, J. Klatt, and S. Read, "Socially optimized learning in virtual environments (SOLVE)," Interactive Storytelling, pp. 182192, 2011.

[6] D. Traum, S. Marsella, J. Gratch, J. Lee, and A. Hartholt, "Multi-party, multi-issue, multi-strategy negotiation for multimodal virtual agents," in IVA. Springer, 2008, pp. 117-130.

[7] L. Thompson, "Negotiation behavior and outcomes: Empirical evidence and theoretical issue." Psychological Bulletin, vol. 108, pp. 515-532, 1990.
[8] M. J. Gelfand, V. M. Smith, J. Raver, and L. Nishii, "Negotiating relationally: The dynamics of the relational self in negotiations." Academy of Management Review, vol. 31, 2006.

[9] C. de Melo and J. Carnevale, P.and Gratch, "The effect of expression of anger and happiness in computer agents on negotiations with humans," AAMAS, 2011.

[10] C. de Melo, P. Carnevale, and J. Gratch, "The effect of virtual agents emotion displays and appraisals on peoples decision making in negotiation," in IVA. Springer, 2012, pp. 53-66.

[11] J. R. Curhan, H. A. Elfenbein, and H. Xu, "What do people value when they negotiate? mapping the domain of subjective value in negotiation,” JPSP, vol. 91, pp. 493-512, 2006.

[12] J. R. Curhan, H. A. Elfenbein, and N. Eisenkraft, "The objective value of subjective value: A multi-round negotiation study," Journal of Applied Social Psychology, vol. 40, no. 3, pp. 690-709, 2010.

[13] R. L. Oliver, P. V. Balakrishnan, and B. Barry, "Outcome satisfaction in negotiation: A test of expectancy disconfirmation." OBHDP, vol. 60, 1994

[14] R. Powell, "Bargaining and learning while fighting," AJPS, vol. 48, no. 2, pp. 344-361, 2004.

[15] B. L. Slantchev, "The principle of convergence in wartime negotiations," APSR, vol. 97, pp. 621-632, 2003.

[16] D. V. Pynadath, N. Wang, and S. C. Marsella, "Computational models of human behavior in wartime negotiations," in CogSci, 2013, p. to appear.

[17] D. Kahneman, "Reference points, anchors, norms, and mixed feelings," OBHDP, vol. 51, no. 2, pp. 296-312, 1992.

[18] M. A. Neale and M. H. Bazerman, Cognition and rationality in negotiation. Free Press, 1991.

[19] D. V. Pynadath and S. C. Marsella, "PsychSim: Modeling theory of mind with decision-theoretic agents," in IJCAI, 2005, pp. 1181-1186.

[20] D. Kahneman and A. Tversky, "Prospect theory: An analysis of decision under risk," Econometrica, pp. 263-291, 1979.

[21] E. C. Dupuis and E. S. Cohn, "A new scale to measure war attitudes: Construction and predictors," Journal of Psychological Arts and Sciences, vol. 3, no. 1, pp. 6-15, 2006.

[22] P. A. M. Van Lange, E. M. N. De Bruin, W. Otten, and J. A. Joireman, "Development of prosocial, individualistic, and competitive orientations: Theory and preliminary evidence," JPSP, vol. 74, no. 4, pp. 733-746, 1997.

[23] R. J. Robinson, R. J. Lewicki, and E. M. Donahue, "Extending and testing a five factor model of ethical and unethical bargaining tactics: Introducing the SINS scale," Journal of Organizational Behavior, vol. 21, pp. 649-664, 2000.

[24] J. M. Kim, R. W. Hill, Jr, P. J. Durlach, H. C. Lane, E. Forbell, M. Core, S. Marsella, D. Pynadath, and J. Hart, "BiLAT: A game-based environment for practicing negotiation in a cultural context," IJAIED, vol. 19, no. 3, pp. 289-308, 2009. 